Revue scientifique sur la conception et l'aménagement de l'espace

$8 \mid 2012$

Les concepteurs de jardins et de parcs japonais

\title{
Présentation de la rubrique « Chercheurs en devenir »
}

Pierre Donadieu

OpenEdition

Journals

Édition électronique

URL : http://journals.openedition.org/paysage/15914

DOI : 10.4000/paysage. 15914

ISSN : 1969-6124

\section{Éditeur :}

École nationale supérieure du paysage de Versailles-Marseille, Institut national des sciences appliquées Centre Val de Loire - École de la nature et du paysage, École nationale supérieure d'architecture et de paysage de Bordeaux, École nationale supérieure d'architecture et de paysage de Lille, Agrocampus Angers

\section{Référence électronique}

Pierre Donadieu, « Présentation de la rubrique « Chercheurs en devenir » », Projets de paysage [En ligne], 8 | 2012, mis en ligne le 07 juillet 2012, consulté le 11 mars 2021. URL : http://

journals.openedition.org/paysage/15914; DOI : https://doi.org/10.4000/paysage.15914

Ce document a été généré automatiquement le 11 mars 2021.

Projets de paysage 


\title{
Présentation de la rubrique «Chercheurs en devenir »
}

\author{
Pierre Donadieu
}

1 Trois articles de jeunes doctorants sont présentés dans ce numéro. Ils ont en commun la compréhension de faits sociaux et spatiaux dans l'espace public urbain de deux pays différents. En Tunisie, Besma Loukil analyse les conditions dans lesquelles les faits de civilité et d'incivilités apparaissent et disparaissent dans les parcs publics; Sondès Zaïder étudie le développement des stations balnéaires sur le littoral tunisien et ses conséquences. Au Japon Alban Mannisi étudie la manière dont le philosophe Kuwako Toshio met en œuvre des modes participatifs efficaces pour les habitants confrontés à des projets d'aménagement de rues pour lesquels ils n'ont pas été consultés.

\section{AUTEUR}

\section{PIERRE DONADIEU}

Professeur à l'École nationale supérieure de paysage de Versailles-Marseille.

p.donadieu[at]icloud[dot]com 